African Journal of Marine Sciences

September 2017, Volume 39 Issue 2 Pages 145-151

http://dx.doi.org/10.2989/1814232X.2017.1327886

http://archimer.ifremer.fr/doc/00399/51017/

(c) NISC (Pty) Ltd

\title{
Relationship between somatic growth and otolith growth: a case study of the ornate jobfish Pristipomoides argyrogrammicus from the coast of Réunion (SW Indian Ocean)
}

\author{
Mahé Kelig ${ }^{1}$, Aumond Yoann ${ }^{1}$, Rabhi Khalef ${ }^{1}$, Elleboode Romain ${ }^{1}$, Bellamy Elise ${ }^{1}$, Huet Jerome ${ }^{1}$, \\ Gault Mandy ${ }^{2}$, Roos David ${ }^{1}$ \\ 1 Ifremer, France \\ ${ }^{2}$ FRS Marine Laboratory, Aberdeen, Scotland \\ * Corresponding author : Kelig Mahé, email address : kelig.mahe@ifremer.fr
}

\begin{abstract}
:
The ornate jobfish Pristipomoides argyrogrammicus Valenciennes 1832 occurs in the Indo-West Pacific Ocean, where it is harvested by small-scale coastal fisheries. Management of this species is hindered by lack of adequate biological data. We sampled a total of 113 individuals from the landings of local artisanal fishers on the island of Réunion (southwestern Indian Ocean), from March 2014 to March 2015. The relationships between two types of body length (total and standard length, $\mathrm{cm}$ ) and total weight $(\mathrm{g})$ were shown to be significant $(\mathrm{p}<0.05)$. The length-weight relationship was described by a power function, with the scaling factor estimated to be 0.008 and the exponent 3.146. Age was determined using whole otoliths. The von Bertalanffy growth equation was estimated to be $T L t=30.68(1$ - e-0.52(t)). Otolith morphometry variables (length, width and area) were significantly correlated with age estimates $(p<0.05)$. No significant difference in age estimates was observed between left and right otoliths used as predictors. Readings from observed age and the estimates from modelled age indicated relatively good agreement, suggesting the potential to use whole otoliths for age estimation.
\end{abstract}

Keywords : age estimate, general linear model, Lutjanidae, modelled age, morphometric parameters, otolith morphometry, reading precision 


\section{Introduction}

The ornate jobfish Pristipomoides argyrogrammicus Valenciennes, 1832 is a member of the snapper family (Lutjanidae), which is one of the important fisheries resources in the tropical and subtropical waters of the Indo-West Pacific (Allen 1985). This species occurs at depths of $70 \mathrm{~m}$ to $350 \mathrm{~m}$ (Anderson and Allen 2001) in the Western Indian Ocean from Kenya to Mauritius Island (Smith and Smith 1963; Allen 1985; Fricke et al. 2009; Wickel and Jamon 2010; Fulanda et al. 2011) and in the Western Pacific Ocean from Japan to New Caledonia (Wass 1984; Allen 1985; Fricke et al. 2011). P. argyrogrammicus is targeted particularly by artisanal fisheries at Reunion Island. The main deep-water tropical fishes - snappers, groupers (Epinephelidae) and emperors (Lethrinidae) - support locally important artisanal fisheries throughout the Indo-Pacific region, but quantitative assessments of these species have been limited by a lack of adequate biological and fisheries data (Newman et al. 2016). Since the 2000s, the fishery for $P$. argyrogrammicus at Reunion Island has increased significantly with the emergence of a new fishing technique, the 'electric fishing reel', employed by commercial and recreational fishermen. Qualitative assessments of Reunion Island deep-water species showed fishing impacts on this stock. The first results showed that the fishing yield and the mean landing size decreased (Fleury et al. 2011, 2012). Moreover, there were no management measures and regulations in place on these fisheries. However, catches of the predators of $P$. argyrogrammicus (Etelis coruscans and E. carbunculus) increased, which seemed to bring about positive effects on the prey population (Roos et al. 2015). Data on P. argyrogrammicus biology are scarce and growth parameters to date have not been documented, with only one study on reproductive biology off Ishigaki Island, Japan (Nanami 2011). In view of the requirement for data, the aim of this study was to investigate the growth of $P$. argyrogrammicus along the coast of Reunion Island, based on an age determination method from otolith readings. The results of this growth study will be used in regional stock assessments and serve as an addition to global knowledge of this ecologically important species. Development of a low-cost ageing technique is an additional benefit of this study. Reliable techniques for estimating age composition of exploited deep-water snapper populations are limited or costly, making alternative ageing techniques necessary in fisheries management. Consequently, the aim of this study was also to contrast $P$. argyrogrammicus ageing based on otolith readings versus evaluation of otolith shape.

\section{Material and methods}

One hundred and thirteen $P$. argyrogrammicus were sampled from Eastern Reunion Island local deep-water handline artisanal fisheries landings. Monthly specimens were collected 
between March 2014 and March 2015. Specimens were examined in the laboratory for sex, total length $(T L, c m)$, fork length $(F L, c m)$, standard length $(S L, c m)$ and total wet weight $(W$, g).

Length-weight relationships were estimated separately for males and females. In order to estimate the parameters of the allometric L-W relationship, a least squared linear model was fitted to the base-10 logarithm of the data:

$$
\begin{gathered}
W=a L^{b} \\
\log W=\log a+b \log L
\end{gathered}
$$

where $a$ is the intercept or initial growth coefficient and $b$ is the slope i.e. the growth coefficient (Le Cren 1951; Ricker 1975; Froese 2006). Analysis of covariance (ANCOVA) was used to assess the differences between the fitted length/weight relationships for males and females.

For ageing, sagittal otoliths were removed from the left and right side of the head of each specimen. Since growth of $P$. argyrogrammicus has not been investigated before, ageing calibration was performed. Calibration was based on contrasting results from multiple ageing techniques. Ageing techniques comprised readings performed on whole otoliths, sectioned otoliths, and scales. Whole otoliths were read under both transmitted and reflected light, both before and after burning. After the otoliths were embedded in epoxy resin, transverse sections (TS) through the core (or nucleus) were made using a precision saw with a blade thickness of $0.3 \mathrm{~mm}$. Finally, the TS were ground and polished on both sides until the core was visible (thickness of $0.2 \mathrm{~mm}$ ). Five scales were extracted from under the pectoral fin to limit the regenerated scales.

Otolith morphometry was also used to develop a faster and cheaper alternative method to obtain fish age. Each otolith was weighed (Ow: otolith weight, $\mathrm{mg}$ ) and was analysed using TNPC software (Digital Processing of Calcified Structures; www.tnpc.fr) in two steps: (1) the extraction of morphometric parameters of the whole otolith $\left(O_{L}=\right.$ otolith length; $O_{W I}=$ otolith width; $O_{A}=$ otolith area and $O_{w}=$ otolith weight).

Each otolith was examined twice by two readers to control for observer bias and estimate reading precision. Coefficient of variation (CV), percent agreement (PA; $\pm 1 \mathrm{y}$ ), and absolute percent error (APE) were used to estimate reading precision (Beamish and Fournier 1981; Kimura and Lions 1991). Precision metrics were calculated as: 


$$
\begin{array}{r}
\mathrm{CV}_{j}(\%)=100 \times \frac{\sqrt{\sum_{i=1}^{R} \frac{\left(X_{\mathrm{ij}}-X_{j}\right)^{2}}{R-1}}}{x_{i}} \\
\mathrm{PA}=\frac{\sum\left|n_{\text {diff }} \leq 1\right|}{n} \\
\operatorname{APE}_{j}(\%)=100 \times \frac{1}{R} \sum_{i=1}^{R} \frac{\left|X_{i j}+X_{j}\right|}{X_{j}}
\end{array}
$$

where $R$ is the number of times each fish is aged, $X_{i j}$ is the $i$ (th) ageing of the $j($ th $)$ fish, $X j$ is the mean age calculated for the $j\left(\right.$ th) fish, and $n_{\text {diff }}$ is the difference in ageing between the first and second readings.

Age and total length data were used to describe growth using the Von Bertalanffy (1938) model for the lengths:

$$
\mathrm{TL}_{t}=\mathrm{TL}_{\infty}\left(1-e^{-K\left(t-t_{0}\right)}\right)
$$

and for the weight:

$$
W_{t}=W_{\infty}\left(1-e^{-K\left(t-t_{0}\right)}\right)^{3}
$$

with

$$
W_{\infty}=a \mathrm{TL}_{\infty}^{b}
$$

where $\mathrm{TL}_{t}$ and $W_{t}$ are the length and the weight at age $t, \mathrm{TL}_{\infty}$ and $W_{\infty}$ the asymptotic length and weight, $K$ the rate at which the asymptote is reached and $t_{0}$ the theoretical age (in years) at zero length (scaling factor). The growth model was performed under the constraint of $t_{0}=$ 0 , because the adjustment of the model with only 2 parameters was better than the initial model without constraint.

Fish growth was estimated using the growth performance index (Pauly and Munro 1984):

$$
\varphi^{\prime}=\log K+2 \log T L_{\infty}
$$

where $K$ and $T L_{\infty}$ are as above. Growth comparison was based on $\varphi$ ' rather than from a comparison of $\mathrm{TL}_{\infty}$ and $K$ individually, since these two parameters are correlated (Sparre et al. 1987). Likelihood ratio tests were used to compare the von Bertalanffy growth curves between sexes (Kimura 1980; Haddon 2001).

The relationship between age estimation from readings, otolith morphometry, and otolith location (left or right side) was investigated using a complete generalised linear model (GLM; 
McCullagh and Nelder 1999). Age estimates were the response variable, and otolith shape and location the independent variables. The age estimation model was

$$
\text { Age } \sim O_{L}+O_{W 1}+O_{A}+O_{W}+S+O_{L} \times S+O_{W 1} \times S+O_{A} \times S+O_{W} \times S
$$

where $\mathrm{S}$ is the side

To predict the probability of accurate otolith readings, a binary logistic regression was used. The same independent variables as above were used in the logistic regression. The response variable was constructed from the age groups identified by readers (ages 1-5). Five groups (Group 1-5) were constructed, each used in a separate logistic model. Categories for the response variable were coded as 1 if belonging to an age group and 0 otherwise. As an example, for the Group 1 model, fish read as age 1 were coded as 1, and fish read as ages $2-5$ were coded as 0 . The logistic model was

$$
\mathrm{Age}_{0 / 1} \sim O_{L}+O_{W 1}+O_{A}+O_{W}+S+O_{L} \times S+O_{W 1} \times S+O_{A} \times S+O_{W} \times S+\varepsilon_{0 / 1}
$$

where $\varepsilon_{0 / 1}$ assumed the binomial distribution

The above model was used independently for each of the five age groups obtained from readings. The overall best model was chosen from the final logistic models using a stepwise selection based on the Akaike information criterion (AIC; Akaike 1974; Sakamo et al. 1986). The probability of falling into either the 0 or the 1 group was calculated for each otolith for each of the five models as (McCullagh and Nelder 1999:

$$
p\left(\text { Age }_{0 / 1}\right)=\frac{\exp \left(O_{L}+O_{W 1}+O_{A}+O_{W}+S+O_{L} \times S+O_{W 1} \times S+O_{A} \times S+O_{W} \times S+\varepsilon_{0 / 1}\right)}{1+\exp \left(O_{L}+O_{W 1}+O_{A}+O_{W}+S+O_{L} \times S+O_{W 1} \times S+O_{A} \times S+O_{W} \times S+\varepsilon_{0 / 1}\right)}
$$

The precision of the age modeled from morphometric parameters was determined from the age estimated by the experts.

All analyses were done in ' $R$ ' (R Core Team 2016).

\section{Results}

Out of 113 P. argyrogrammicus collected from February to December 2004, two were juveniles, 52 males and 59 females. Male and female measured length (TL) and weight (W) ranged respectively from $14 \mathrm{~cm}$ to $32 \mathrm{~cm}$ and from $31 \mathrm{~g}$ to $418 \mathrm{~g}$. Significant $L-L$ and $L-W$ relationships $(p<0.05)$ were detected: 


$$
\begin{gathered}
\mathrm{TL}=1.232 \mathrm{SL}+0.498 ; r^{2}=0.99 ; p<2.10^{-16} \\
\mathrm{TL}=1.150 \mathrm{FL}+0.265 ; r^{2}=0.99 ; p<2.10^{-16} \\
\quad W=0.008 \mathrm{TL}^{3.146} ; r^{2}=0.99 ; p<2.10^{-16}
\end{gathered}
$$

The length-weight relationship showed a significant positive allometric growth (greater than $3)$, regardless of the sex of individuals [Figure 1]. The sex effect was not significant on TLSL $(p=0.753)$, TL-FL $(p=0.424)$ and TL- $W(p=0.925)$ relationships.

Whole otolith was found to be the best technique, providing very clear visible alternating translucent and opaque bands (Figure 2). The observed ages of $P$. argyrogrammicus ranged from 1 to 5 years (Figure 3). Whole otolith readings indicated good agreement between estimates (agreement $=83.8 \%, \mathrm{CV}=3.5 \%$ and APE $=3.1 \%$ ). Von Bertalanffy growth parameters for females $(n=59)$ and males $(n=52)$ were $\mathrm{TL}_{\infty}=30.97 \mathrm{~cm} ; W_{\infty}=383.91 \mathrm{~g} ; \mathrm{K}$ $=0.54 \mathrm{y}^{-1}$ and $\mathrm{TL}_{\infty}=28.99 \mathrm{~cm} ; W_{\infty}=323.38 \mathrm{~g} ; K=0.52 \mathrm{y}^{-1}$, respectively. These results translated into similar growth performance indices for females $\left(\varphi^{\prime}=2.71\right)$ and males $\left(\varphi^{\prime}=\right.$ 2.68). No significant differences in growth parameters was found between sexes (likelihood ratio test: $\left.\pi^{2}=0.532, \mathrm{df}=3, p=0.465\right)$. The estimated growth parameters for both sexes combined were: $\mathrm{TL}_{\infty}=30.68 \mathrm{~cm} ; W_{\infty}=380.75 \mathrm{~g}$; and $K=0.52 \mathrm{y}^{-1}$.

Three morphometric parameters of the otolith $\left(O_{L}, p=0.041 ; O_{A}, p<0.001 ; O_{\mathrm{Wl}}, p=0.009\right)$ were significantly correlated with age estimates from whole-otolith readings, following GLM analysis (Table 1). Logistic regression using GLM significant predictors showed $O_{L}$ to be significant in all but the Group 5 model. Predictors $O_{W 1}$ and $O_{A}$ were significant in Group 3 models. Predictor $O_{W}$ was significant in groups 2 and 5 models (Table 2). The precision of the modelled age decreased with age (Table 3 ). The bias between observed age and modelled age was low (agreement $=77.9 \%, \mathrm{CV}=5.5 \%$ and $\mathrm{APE}=6.5 \%$ ).

\section{Discussion}

Ornate jobfish contribute to important fisheries in the tropical and subtropical waters of the Indo-West Pacific, particularly the Reunion Island artisanal fisheries. For this reason, data on the biology of this species are key for effective stock assessment for global and local populations (Froese 2006). The length range observed in this study was similar to that of other studies on this species in the Pacific Ocean (Nanami 2011). This study showed that total, fork, and standard lengths are highly correlated, which makes data based on lengths taken from different methods interchangeable. Sex in this study did not show an effect on morphometric variables, contrary to the data observed in the China Sea (Nanami 2011). This 
difference could be due to environmental conditions and genetic traits of ornate jobfish stocks from different geographical areas and sampling periods. Fish body measurements may change with reproduction phase (gonad development and spawning period) or feeding activities (food availability and feeding rate; Wootton 1990). The length-weight relationship showed a significant positive allometric growth $(b=3.15)$, confirming data from other geographical areas, such as the south-west of Japan $(b=3.12$; Nanami, 2011), the Vanuatu islands ( $b=3.22$; Brouard and Grandperrin, 1984; Pakoa, 1998), the Mariana Archipelago (b $=3.14$; Ralston, 1988) and the Gulf of Suez ( $b=3.02$; Mehanna, 2003).

Estimates of age in tropical deep-water fishes, especially snappers, have been obtained from several different calcified structures (scales, fin spines, vertebrae, whole otoliths and sectioned otoliths; Newman et al. 2016). In temperate waters, the formation of translucent zones is generally considered to occur during winter, whereas opaque zones are formed during the rapid growth periods of spring and summer. This pattern is linked to temporal fluctuations in metabolism and water temperature, where seasonal temperature variations exceed 3-4 ${ }^{\circ} \mathrm{C}$ (Høie et al. 2008; Neat et al. 2008). Consequently, the age of tropical deepwater fishes, where seasonal temperature differences are slighter, is more difficult to estimate than those of temperate waters fishes. In this study, ageing based on whole otolith were of similar accuracy than that from sectioned otoliths, contrary to what has been shown in other Pristipomoides species (Newman et al. 2016). Ages from this study ranged between 1 and 5 years. The only previous ageing work for ornate jobfish was by Fry et al. (2006), who used four specimens with estimated ages ranging from 4 to 6 years. Our study, therefore, showed a good agreement as to the possible maximum age for our target species.

This is the first study to document the von Bertalanffy growth function for $P$. argyrogrammicus (Figure 4). The lower growth and the growth performance index of this species compared with those from other Pristipomoides could be explained by: (1) speciesspecific differences; (2) variations in environmental conditions (such as temperature and food availability) among sampled areas; (3) different size distributions (probably caused by different types of sampling gear); and (4) sex ratio when there was sexual dimorphism. No significant difference in growth parameters for $P$. argyrogrammicus was observed between sexes, contrary to $P$. multidens (Newman and Dunk 2003). This result may make sex-specific fishery regulations unnecessary. Several growth studies of Pristipomoides species have been reported for the Pacific Ocean, but only one for the Indian Ocean, namely for $P$. filamentosus (Pilling et al. 2000). The growth difference between Pristipomoides species could also be accounted for by the more favourable environmental conditions of the Pacific 
Ocean, where the maximum total length for $P$. argyrogrammicus was $45.7 \mathrm{~cm}$ (Anderson and Allen 2001).

Between 800000 and 1000000 otoliths are sampled and analysed per year for stock assessment for an annual cost of approximately CAN\$ 8000000 (Campana and Thorrold 2001; ICES 2011). The lengthiest step in this process is the preparation and the reading of otoliths. As routine age estimation for deep-water snapper populations from otolith readings is costly, other alternative approaches must be developed, such as age estimation from whole otoliths. Otolith biomineralisation results from interactions of many internal (physiological) and external (environmental) factors (Campana and Nielson 1985; MoralesNin 2000; Allemand et al. 2007). Age may even be predicted by the otolith morphological features (Ochwada et al. 2008). Three variables describing whole otolith morphometry were significantly correlated in this study with the age of $P$. argyrogrammicus. When considering left or right otoliths, there was no difference in age estimates using their morphometric parameters. This result was expected, based on a study that showed that only the flatfishes had otolith shape differences between head sides (Mille et al. 2015). Among the morphometric parameters of whole otoliths, several authors have shown that a significant relationship between the otolith weight (Ow) and fish age exists (Boehlert 1985; Cardinale et al. 2000; Labropoulou and Papaconstantinou 2000; Arayaa et al. 2001; Cardinale and Arrhenius 2004; McDougall 2004; Ochwada et al. 2008; Steward et al. 2009; Beyer and Szedlmayer 2010; Williams et al. 2015; Mahé et al. 2016a). The species in these studies were long-lived, whereas $P$. argyrogrammicus is short-lived, with maximum observed age of five years, according to our observations. Otolith weight was the only parameter in this study taking into account growth in three dimensions. In similar studies, a significant relationship between otolith radius and fish age was observed in Hippoglossoides platessoides (Fossen et al. 2003) and Trematomus newnesi (Mahé et al. 2016b), attributed to the low thickness of the otolith. The relationship between age and the different morphometric parameters of otolith could change with time. Radtke et al. (1985) showed that age could be predicted by $O_{L}$ and $O_{W 1}$ with a good precision at the early life stages. For older fish, $O_{W}$ was shown to be a better variable. For young $P$. argyrogrammicus, $O_{w}$ had no significant effect on age estimation. For older individuals (Age 3 and Age 5), however, $O_{W}$ was significant in age growth models. During the life of $P$. argyrogrammicus, the length and the width of the otolith increase with the fish length and after a certain age is reached, the otolith only continues to increase in thickness.

Our study shows the effectiveness in age estimation precision using several morphometric parameters of whole otoliths (Troynikov and Robertson 2005; Ochwada et al. 2008). The 
precision of $5.5 \% \mathrm{CV}$ observed in this study was superior than the common level of precision in the ageing studies using conventional methods ( $C V=7.6 \%$ from a review of 117 ageing papers, Campana 2001). The approach used in this study is less costly and faster when predicting age and it can be applied for many species. However, to estimate precision, our method must be calibrated with age-length keys derived from samples of the same region and-time.

\section{Conclusion}

Among snapper species, $P$. argyrogrammicus showed slower growth. Age estimation using morphological parameters of whole otoliths showed a good precision ( $C V=5.5 \%$ ), similar to that shown for other snappers, namely Lutjanus campechanus (Beyer and Szedlmayer 2010) and Pristipomoides filamentosus (Williams et al. 2015). However, using this technique requires calibration based on age readings using traditional techniques. We recommend age estimation using whole otoliths as an alternative method of ageing adult fish, especially short-lived fish from regions with data-poor fisheries.

Acknowledgements - This study was carried out with the financial support of the European project 'ANCRE-DMX2' (Indicateurs biologiques et écologiques pour une gestion durable des stocks de poissons DéMersauX profonds d'intérêt halieutique à La Réunion). We also thank all fishermen and colleagues who helped us in the field, and anonymous reviewers for their comments and suggestions.

\section{References}

Akaike H. 1974. A new look at the statistical model identification. IEEE Transactions on Automatic Control 19: 716-723.

Allemand D, Mayer-Gostan N, Pontual H De, Bœuf G, Payan P. 2007. Fish otolith calcification in relation to endolymph chemistry. In: Bäuerlein E (ed.) Handbook of biomineralization. Germany: Wiley-VCH Verlag GmbH. pp 291-308.

Allen GR. 1985. FAO species catalogue. Vol 6. Snappers of the world. An annotated and illustrated catalogue of lutjanid species known to date. FAO Fisheries Synopsis 125. Rome: Food and Agriculture Organisation.

Anderson WD Jr, Allen GR. 2001. Lutjanidae. Jobfishes. In: Carpenter KE, Niem V (eds), FAO species identification guide for fishery purposes. The living marine resources of the Western Central 
Pacific. Vol. 5. Bony fishes part 3 (Menidae to Pomacentridae). Rome: Food and Agriculture Organisation. pp 2840-2918.

Arayaa M, Cubillosb LA, Guzmán M, Penãililloa J, Sepúlveda A. 2001. Evidence of a relationship between age and otolith weight in the Chilean jack mackerel, Trachurus symmetricus murphyi (Nichols). Fisheries Research 51: 17-26.

Beamish RJ, Fournier DA. 1981. A method for comparing the precision of a set of age determinations. Canadian Journal of Fisheries and Aquatic Sciences 38: 982-983.

Beyer SG, Szedlmayer ST. 2010. The use of otolith shape analysis for ageing juvenile red snapper, Lutjanus campechanus. Environmental Biology of Fishes 89: 333-340.

Boehlert GW. 1985. Using objective criteria and multiple regression models for age determination in fishes. Fishery Bulletin 83: 103-117.

Brouard F, Grandperrin R. 1984. Deep-bottom fishing in Vanuatu: initial results. SPC Fisheries Newsletter 28: 21-25.

Campana SE. 2001. Accuracy, precision and quality control in age determination, including a review of the use and abuse of age validation methods. Journal of Fish Biology 59: 197-242.

Campana SE, Neilson JD. 1985. Microstructure of fish otoliths. Canadian Journal of Fisheries and Aquatic Sciences 42: 1014-1031.

Campana SE, Thorrold SR. 2001. Otoliths, increments and elements: keys to a comprehensive understanding of fish populations? Canadian Journal of Fisheries and Aquatic Sciences 58: 30-38.

Cardinale M, Arrhenius F. 2004. Application of the otolith weight-age relationship to estimate the agestructure of haddock (Melanogramus aeglefinus). Journal of Applied Ichthyology 20: 470-475.

Cardinale M, Arrhenius F, Johnsson B. 2000. Potential use of otolith weight for the determination of age-structure of Baltic cod (Gadus morhua) and plaice (Pleuronectes platessa). Fisheries Research 45: 239-252.

Fleury PG, Aureche V, Le Ru L. 2011. Evolution des captures de poissons démersaux profonds, au vire-ligne électrique, dans l'ouest de la Réunion, entre 2000 et 2011. Rapport Ifremer RSTDOI- 2011-06. La Réunion : Ifremer. 
Fleury PG, Evano H, Le Ru L, Aureche V. 2012. Synthèse de l'étude et des campagnes à la mer 2011 sur l'exploitation aux vire-lignes des espèces démersales profondes autour de La Réunion. Rapport Ifremer RST-DOI- 2012-13. La Réunion : Ifremer.

Fossen I, Albert OT, Nilssen EM. 2003. Improving the precision of ageing assessments for long rough dab by using digitized pictures and otolith measurements. Fisheries Research 60: 53-64.

Fricke R, Kulbicki M, Wantiez L. 2011. Checklist of the fishes of New Caledonia, and their distribution in the Southwest Pacific Ocean (Pisces). Stuttgarter Beiträge zur Naturkunde A 4: 341-463.

Fricke R, Mulochau TPD, Chabanet P, Tessier E, Letourneur Y. 2009. Annotated checklist of the fish species (Pisces) of La Réunion, including a Red List of threatened and declining species. Stuttgarter Beitraege zur Naturkunde A 2: 1-168.

Froese R. 2006. Cube law, condition factor and weight-length relationships: history, meta-analysis and recommendations. Journal of Applied Ichthyology 22: 241-253.

Fry GC, Brewer DT, Venables WN. 2006. Vulnerability of deepwater demersal fishes to commercial fishing: evidence from a study around a tropical volcanic seamount in Papua New Guinea. Fisheries Research 81: 126-141.

Fulanda B, Ohtomi J, Mueni E, Kimani E. 2011. Fishery trends, resource-use and management system in the Ungwana Bay fishery Kenya. Ocean and Coastal Management 54: 401-414.

Haddon M. 2001. Modelling and quantitative methods in fisheries. New York: Chapman Hall/CRC.

Høie H, Folkvord A, Mosegaard H, Li L, Worsøe Clausen L, Norberg B et al. 2008. Restricted fish feeding reduces cod otolith opacity. Journal of Applied Ichthyology 24: 138-143.

ICES 2011. Report of the Workshop of National Age Readings Coordinators (WKNARC), 5-9 September 2011, Boulogne-sur-Mer, France. ICES CM 2011/ACOM:45. Copenhagen: International Council for the Exploration of the Sea.

Kimura DK. 1980. Likelihood methods for the von Bertalanffy growth curve. Fishery Bulletin 77: 765776.

Kimura DK, Lyons JL. 1991. Between-reader bias and variability in the ageing process. Fishery Bulletin 89: 53-60. 
Labropoulou M, Papaconstantinou C. 2000. Comparison of otolith growth and somatic growth in two macrourid fishes. Fisheries Research 46: 177-188.

Le Cren ED. 1951. The length-weight relationship and seasonal cycle in gonad weight and condition in the perch (Perca fluviatilis). Journal of Animal Ecology 20: 201-219.

Mahé K, Rabhi K, Bellamy E, Elleboode R, Aumond Y, Huet J et al. 2016a. Growth of the obliquebanded grouper (Epinephelus radiatus) on the coasts of Reunion Island (SW Indian Ocean). Cybium 40: 61-65.

Mahé K, Elleboode R, Loots C, Koubbi P. 2016b. Growth of an inshore Antarctic fish, Trematomus newnesi (Nototheniidae), off Adelie Land. Polar Science 10: 167-172.

Manooch CS. 1987. Age and growth of snappers and groupers. In: Polovina JJ, Ralston S (eds), Tropical snappers and groupers: biology and fisheries management. Ocean Resour. Mar. Policy Ser. Ocean resources and marine policy seriesBoulder and London: Westview Press Inc. pp 329-373.

McCullagh P, Nelder JA. 1999. Generalized linear models (2nd edn). New York: Chapman \& Hall/CRC Monographs on Statistics \& Applied Probability.

Mehanna SF. 2003. Population dynamics of the bigeye snapper Lutjanus lineolatus, Ruppell, 1829 (Family: Lutjanidae) from the Gulf of Suez. Egyptian Journal of Aquatic Biology and Fisheries 7: 71-85.

McDougall AJ. 2004. Assessing the use of sectioned otoliths and other methods to determine the age of the centropomid fish, barramundi (Lates calcarifer) (Bloch) using known age fish. Fisheries Research 67: 129-141.

Mille T, Mahé K, Villanueva CM, De Pontual H, Ernande B. 2015. Sagittal otolith morphogenesis asymmetry in marine fishes. Journal of Fish Biology 87: 646-663.

Morales-Nin B. 2000. Review of the growth regulation processes of otolith daily increment formation. Fisheries Research 46: 53-67.

Nanami A. 2011. Size composition and reproductive biology of the ornate jobfish Pristipomoides argyrogrammicus (Lutjanidae) off Ishigaki Island, Okinawa. Ichthyological Research 58: 310314. 
Neat FC, Wright P, Fryer RJ. 2008. Temperature effects on otolith pattern formation in Atlantic cod Gadus morhua. Journal of Fish Biology 73: 2527-2541.

Newman SJ, Dunk IJ. 2003. Age validation, growth, mortality and additional population parameters of the goldband snapper (Pristipomoides multidens) off the Kimberley coast of northwestern Australia. Fishery Bulletin 101: 116-128.

Newman SJ, Williams AJ, Wakefield CB, Nicol SJ, Taylor BM, O'Malley JM. 2016. Review of the life history characteristics, ecology and fisheries for deep-water tropical demersal fish in the IndoPacific region. Reviews in Fish Biology and Fisheries 26: 537-562.

Ochwada FA, Scandol JP, Gray CA. 2008. Predicting the age of fish using general and generalized linear models of biometric data: a case study of two estuarine finfish from New South Wales, Australia. Fisheries Research 90: 187-197.

Pakoa K. 1998. Vital statistics of marine fishes of Vanuatu. Fisheries section of the network of tropical aquaculture and fisheries professionals. Fisheries department, Port Vila, Vanuatu, NAGA 21: 27-29.

Pauly D, Munro JL. 1984. Once more on growth comparison in fish and invertebrates. FishByte 2: 121.

Pilling GM, Miller RS, Easey MW, Mees CC, Rathacharen S, Azemia R. 2000. Validation of annual growth increments in the otoliths of the lethrinid Lethrinus mahsena and the lutjanid Aprion virescens from sites in the tropical Indian Ocean, with notes on the nature of growth increments in P. filamentosus. Fishery Bulletin 98: 600-611.

R Core Team. 2016. R: a language and environment for statistical computing. Vienna: R Foundation for Statistical Computing.

Radtke RL, Fine ML, Bell J. 1985. Somatic and otolith growth in the oyster toadfish (Opsanus tau L.). Journal of Experimental Marine Biology and Ecology 90: 259-275.

Ralston S, Williams HA. 1988. Depth distributions, growth, and mortality of deep slope fishes from the Mariana Archipelago. NOAA Technical Memorandum NMFS. NOAA-TM-NMFS-SWFC-113. Southwest Fisheries Centre, National Oceanic and Atmospheric Administration.

Ralston S. 1988. Length-weight regressions and condition indices of lutjanids and other deep slope fishes from the Mariana Archipelago. Micronesica 21: 189-197. 
Ricker WE. 1975. Computation and interpretation of the biological statistics of fish populations. Bulletin of the Fisheries Research Board of Canada 191: 1-382.

Roos D, Aumond Y, Huet J, Bruchon F. 2015. Indicateurs biologiques et écologiques pour une gestion durable des stocks de poissons démersaux profonds (100-700 m) d'intérêt halieutique à La Réunion: Projet ANCRE-DMX2, mesure no. 3.6 du volet Réunion du P.P FEP 2007-2013, Convention no. 40055/DMSOI/2013. RST/RBE-DOI/2015-11. La Reunion, IFREMER

Sakamo Y, Ishiguro M, Kitagawa G. 1986. Akaike information criterion statistics. Netherlands: D Reidel Publishing Company.

Smith JLB, Smith MM. 1963. The fishes of Seychelles. Grahamstown: Rhodes University, Department of Ichthyology.

Sparre P, Ursin E, Venema SC. 1987. Introduction to tropical fish stock assessment. FAO Fisheries Technical Paper 306. Rome: Food and Agriculture Organisation.

Steward CA, Demaria KD, Shenker JM. 2009. Using otolith morphometrics to quickly and inexpensively predict age in the gray angelfish (Pomacanthus arcuatus). Fisheries Research 99: $123-129$.

Troynikov VS, Robertson SG. 2005. Estimating age composition using the Fredholm first-kind equation. Marine and Freshwater Research 56: 745-751.

Von Bertalanffy L. 1938. A quantitative theory of organic growth. Human Biology 10: 181-213.

Wass RC. 1984. An annotated checklist of the fishes of Samoa. National Oceanographic and Atmospheric Administration, National Marine Fisheries Service, Special Scientific ReportFisheries 781: 1-51.

Wickel J, Jamon A. 2010. Inventaire taxonomique actualisé des poissons marins de l'île de Mayotte et des bancs récifaux de Geyser-Zélée, Canal de Mozambique. Liste révisée des espèces et élaboration d'une base de données fonctionnelle. Rapport LAGONIA/APNEE en collaboration avec l'Aquarium de la Réunion.

Williams AJ, Newman SJ, Wakefield CB, Bunel M, Halafihi T, Kaltavara J et al. 2015. Evaluating the performance of otolith morphometrics in deriving age compositions and mortality rates for assessment of data-poor tropical fisheries. ICES Journal of Marine Science 72: 2098-2109.

Wootton RJ. 1990. Ecology of teleost fish. London: Chapman and Hall. 


\section{Figure legends}

Figure 1: Total length-total weight relationship of Pristipomoides argyrogrammicus from Reunion Island; female: (black line, + ), and male: (grey dashed line, $x)(n=113)$.

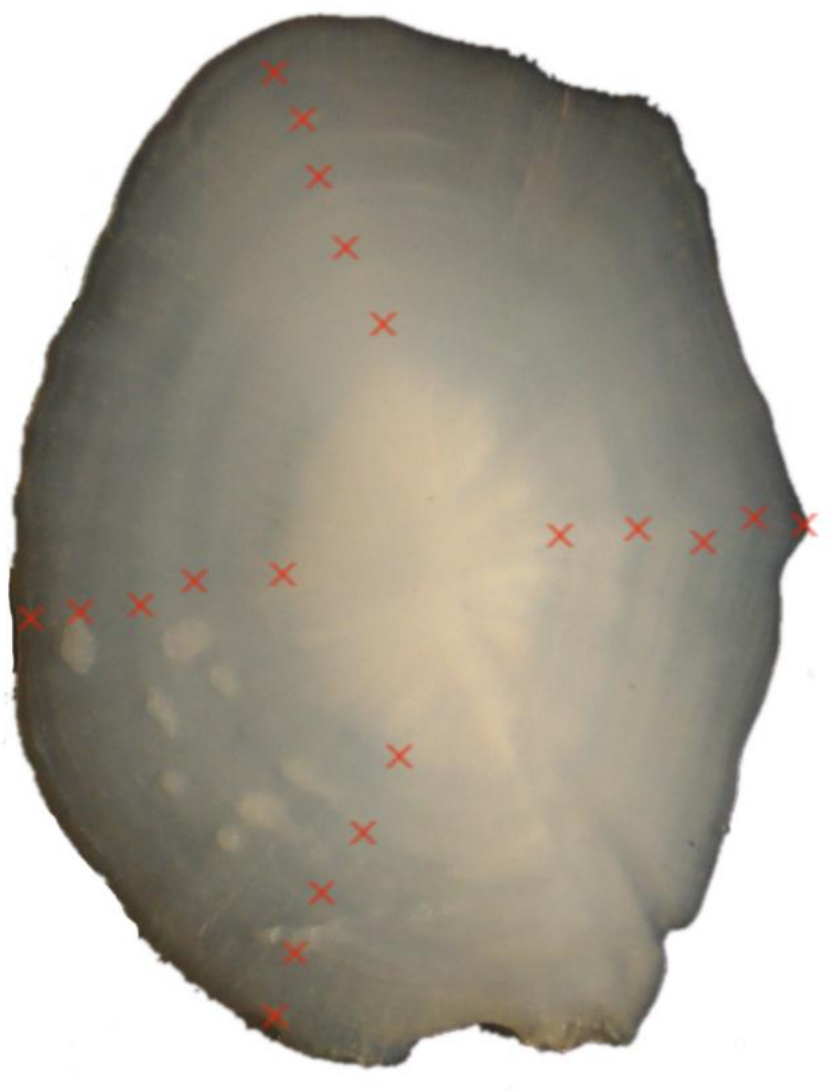

$5 \mathrm{~mm}$ 
Figure 2: Whole otolith of Pristipomoides argyrogrammicus (TL= $27 \mathrm{~cm}$; catch date: July 2014) using reflected light. Growth increments are indicated by red crosses

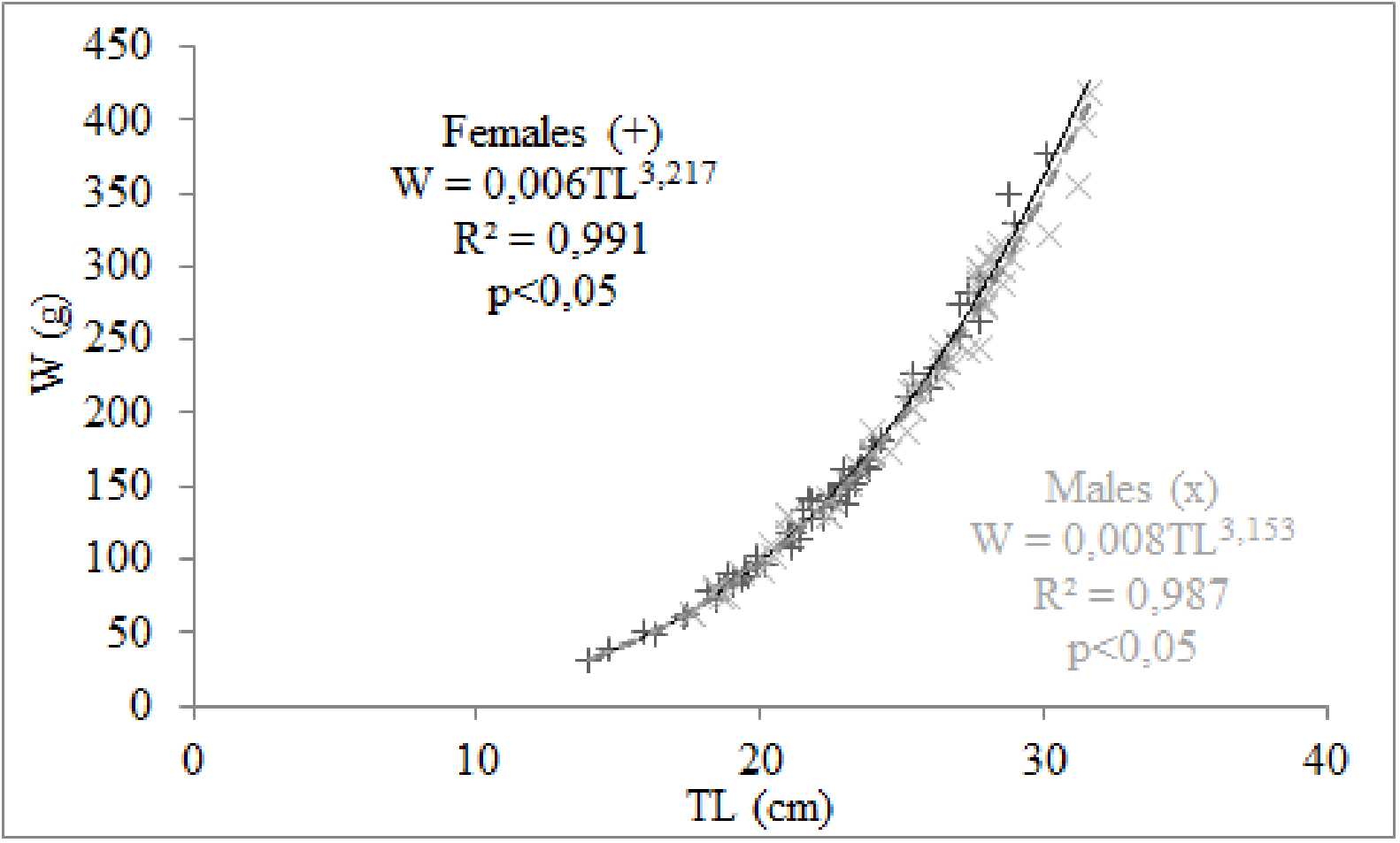

Figure 3: The von Bertalanffy growth curves of Pristipomoides argyrogrammicus from Reunion Island

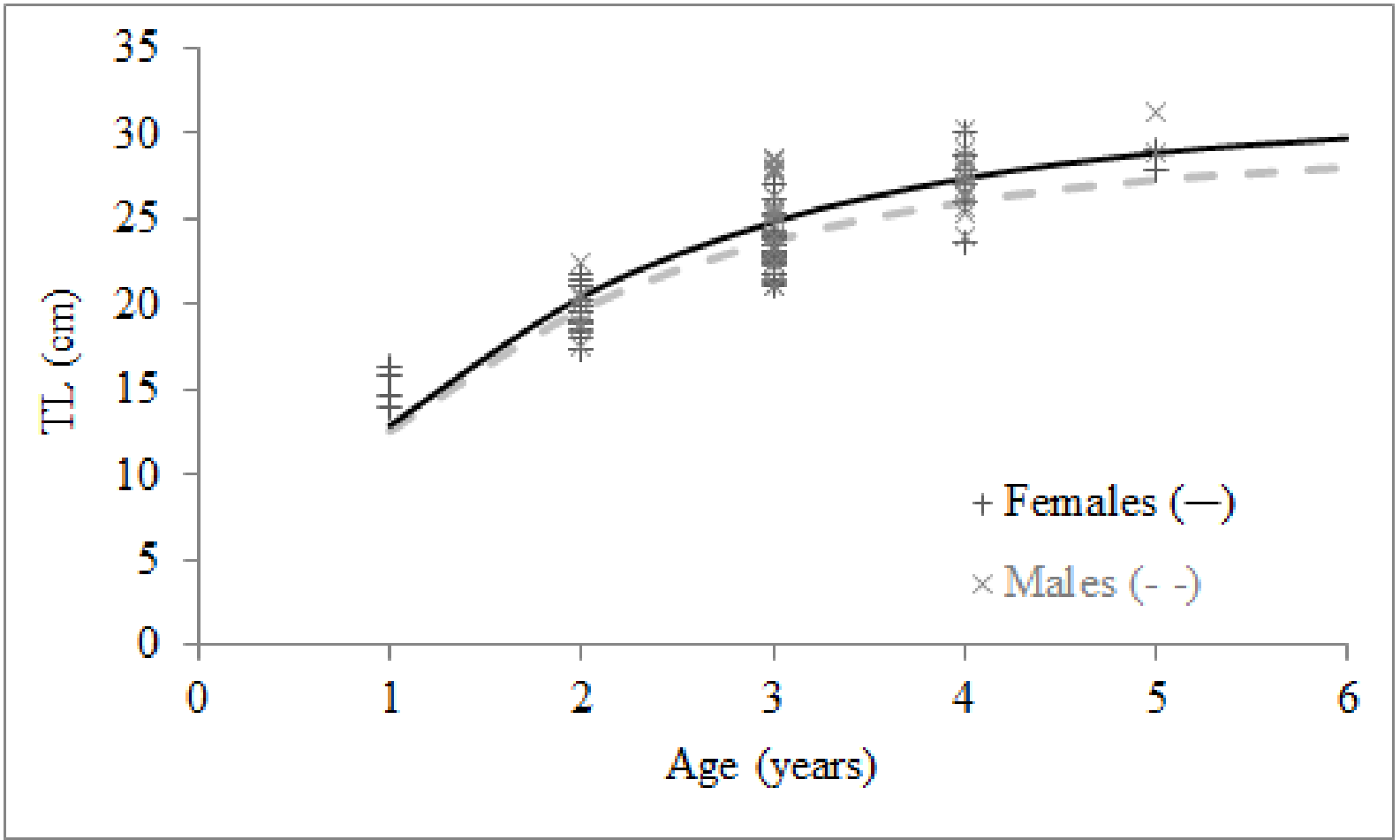


Figure 4: Growth comparison of different Pristipomoides species in the southern hemisphere (a) Ralston and Williams 1988; (b) Pilling et al. 2000; (c) Fry et al. 2006; (d) Manooch 1987). The value of growth performance index $\left(\varphi^{\prime}\right)$ is expressed in the brackets.

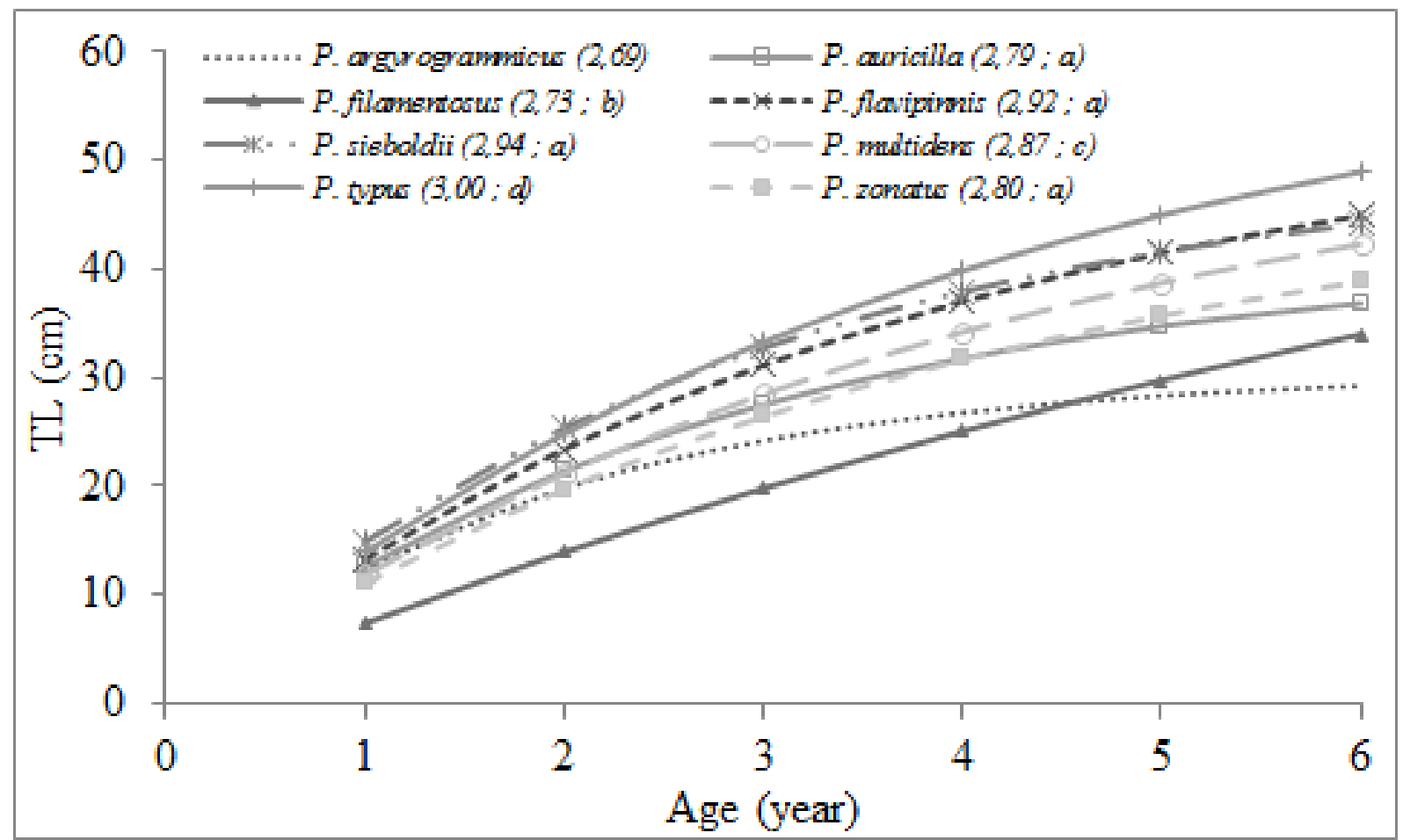


Table 1: General linear model age estimation summary statistics for Pristipomoides argyrogrammicus from Reunion Island. The factors are defined in the text

\begin{tabular}{|c|c|c|}
\hline Factors & $F$ & $p$ \\
\hline$O_{L}$ & 0.718 & 0.041 \\
\hline$O_{\mathrm{WI}}$ & 7.091 & 0.009 \\
\hline$O_{A}$ & 14.616 & $210^{-4}$ \\
\hline$O_{W}$ & 1.663 & 0.199 \\
\hline$O_{L} \times S$ & 0.389 & 0.534 \\
\hline$O_{W 1} \times S$ & 0.065 & 0.799 \\
\hline$O_{A} \times S$ & 0.123 & 0.727 \\
\hline$O_{W} \times S$ & 1.292 & 0.258 \\
\hline
\end{tabular}

Table 2: Summary statistics for the logistic model for age estimation of Pristipomoides argyrogrammicus from Reunion Island

\begin{tabular}{|c|c|c|c|c|}
\hline \multirow{2}{*}{ Age group } & \multicolumn{4}{|c|}{ Morphometric parameters } \\
\cline { 2 - 5 } & $O_{L}$ & $O_{\mathrm{W} 1}$ & $O_{A}$ & $O_{W}$ \\
\hline G1 & 0.0020 & & & \\
\hline G2 & 0.0073 & & & 0.0046 \\
\hline G3 & 0.0264 & 0.0000 & 0.002 & \\
\hline G4 & 0.0008 & & & \\
\hline G5 & & & & 0.0130 \\
\hline
\end{tabular}

Table 3: Age error matrix of modelled versus estimated pairwise comparisons obtained from morphometric parameters of whole otoliths $(n=113)$. Numbers in tables are number of observations. Grey cells are 1:1 ratios

\begin{tabular}{|c|c|c|c|c|c|c|}
\hline & & \multicolumn{5}{|c|}{ Observed age (year) } \\
\hline & & G1 & G2 & G3 & G4 & G5 \\
\hline \multirow{5}{*}{ 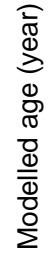 } & G1 & 9 & & & & \\
\hline & G2 & & 21 & & & \\
\hline & G3 & & 3 & 47 & 12 & 1 \\
\hline & G4 & & 1 & 4 & 8 & 2 \\
\hline & G5 & & & & 2 & 3 \\
\hline
\end{tabular}

